\title{
Special issue on asperity contacts and lubrication aspects
}

\author{
Enrico Ciulli · Friedrich Franek
}

Published online: 23 February 2011

(C) Springer Science+Business Media B.V. 2011

Several years ago-supported by Prof. Joze Vizintin, University Ljubljana - an idea already earlier discussed upon suggestion of Prof. Roberto Bassani, University Pisa, was "revitalized", viz to set-up a regular Central and South European congress on tribology. Thus the national tribology societies of Slovenia, Italy, Austria and, successively, Switzerland formed a consortium that decided to organize a biennial conference in the field of tribology with a cycle of venues in turn located in the member states. The AIMETA International Tribology Conference (AITC), formerly organised by the Tribology Group of AIMETA, merged in this conference since its first edition. This conference, named ECOTRIB (European COnference on TRIBology), is to focus on both, the national R\&D activities (at least predominantly, yet not without an international perception) and the challenges that derive from economy and ecology (ECO) issues in modern science and technology.

\section{E. Ciulli $(\bowtie)$}

Dipartimento di Ingegneria Meccanica, Nucleare e della Produzione, University of Pisa, Largo Lucio Lazzarino, 56126 Pisa, Italy

e-mail: ciulli@ing.unipi.it

\section{F. Franek}

Department for Microsystem Technology, Institute of Sensor and Actuator Systems, Vienna University of Technology, Floragasse 7/2, 1040 Wien, Austria e-mail: Friedrich.Franek@TUWien.ac.at
In tribology surface properties of components play a major role in the functionality of a system. Thus it is feasible to overcome functional drawbacks due to friction by understanding the influence of roughness, material properties and interactions between solid and lubricants.

This special issue of MECCANICA compiles a number of extended papers selected from the 2nd ECOTRIB 2009 presentations. The conference, held in Pisa, Italy, in June 2009, was attended by 180 delegates from 33 countries. A major topic was "Asperity contacts and lubrication aspects". Different aspects are addressed by the authors, from the point of view of surface description, surface characterisation, testing, material selection, and technology. Starting from micro and nano tribology aspects, surface roughness and texturing effects on dry and lubricated contacts are investigated. Friction and wear related problems are evidenced and investigations on some bearings are also presented.

This collection of papers is to give an overview of this specific subject interesting for scientific work as well as for applied tribology and to make-perhapsnon-tribologists interested in this field of research and tribology at all.

The guest editors would like to thank all authors and reviewers, the editor and the editorial staff of MECCANICA. 